\title{
THE INFLUENCE OF THE TOOL SURFACE TEXTURE ON FRICTION AND THE SURFACE LAYERS PROPERTIES OF FORMED COMPONENT
}

\author{
Jana Šugárová1, Peter Šugár1, Martin Frnčík', Martin Necpal', Jana Moravčíková', Martin Kusý² \\ 1 Slovak University of Technology, Faculty of Materials Science and Technology, Institute of Production \\ Technologies, J. Bottu 25, 91724 Trnava, Slovakia, e-mail: jana.sugarova@stuba.sk, peter.sugar@stuba.sk, \\ martin.frncik@stuba.sk,martin.necpal@stuba.sk \\ 2 Slovak University of Technology, Faculty of Materials Science and Technology, Institute of Materials Science, \\ J. Bottu 25, 91724 Trnava, Slovakia, e-mail: martin.kusy@stuba.sk
}

Received: 2017.11.22

Accepted: 2018.02.01

Published: 2018.03.01

\begin{abstract}
The morphological texturing of forming tool surfaces has a high potential to reduce friction and tool wear and also has an impact on the surface layers properties of formed material. In order to understand the effect of different types of tool textures, produced by nanosecond fibre laser, on the tribological conditions at the interface tool-formed material and on the integrity of formed part surface layers, the series of experimental investigations have been carried out. The coefficient of friction for different texture parameters (individual feature shape, including the depth profile of the cavities and orientation of the features relative to the material flow) was evaluated via a Ring Test and the surface layers integrity of the formed material (surface roughness and subsurface micro hardness) was also experimentally analysed. The results showed a positive effect of surface texturing on the friction coefficients and the strain hardening of test samples material. Application of surface texture consisting of dimple-like depressions arranged in radial layout contributed to the most significant friction reduction of about $40 \%$. On the other hand, this surface texture contributed to the increase of surface roughness parameters, Ra parameter increased from $0.49 \mu \mathrm{m}$ to $2.19 \mu \mathrm{m}$ and the Rz parameter increased from $0.99 \mu \mathrm{m}$ to $16.79 \mu \mathrm{m}$.
\end{abstract}

Keywords: laser surface texture, dimple shape, dimple arrangement, friction coefficient, surface integrity.

\section{INTRODUCTION}

Reduction of friction and wear through improved lubrication is a pressing concern in the design of tooling and any technologies that improve the lubrication condition are therefore of great interest [1]. Reduction in friction and wear loss has been interests for tribologists and lubrication engineers for years. Recently, surface texturing on the micro-scale level has been introduced to improve lubrication and lower friction of tribological pairs [2]. Properties such as efficiency, reliability and durability of such components depend on the friction that occurs at the contact interface. In addition, there is always the need to increase the load capacity of machine elements, which of course will lead to higher severity of surface in- teraction. Both the need to reduce friction and the desire to increase load capacity require effective lubrication strategy for sliding surfaces [3].

Laser surface texturing technology (LST) is an emerging effective method for improving tribological performance of friction pairs working in dry contact regime or lubricated with oil. In LST technology, a pulsed laser beam is used to create thousands of arranged micro-depressions on a surface by a material ablation process [3, 4]. Different texturing elements, e.g. dimples $[5,6,7]$, crossed and parallel microchannels [8, 9], triangles [10], squares [11], as well as other more complex shapes $[12,13]$, have been studied worldwide for tailor tribological performance, however, the most common texturing features are still circular dimple-like depressions, because of 
their easy fabrication $[5,14]$. As far as dry contacts are concerned, fewer publications compared to lubricated contacts deal with benefits of surface texturing. Most of the published works are related to the entrapment of wear debris or reducing the contact area, for example [15]. The major influencing surface texture parameters are the geometry of surface textures (shape), the area density, the aspect ratio and the relative orientation of the surface textures compared to sliding direction [16]. For example, a significant improvement of friction behaviour using a surface texture consisting of dimple-like depressions with density of 6 $\%$ was observed in lubrication-free regime. In this case, surface texture contributed to friction reduction to about of $47 \%$ [17].

Many researchers have focused on the optimizing of the dimensional parameters mainly of the dimple-like depressions. A lot of experimental researches were carried out in order to define the optimal texture density, the aspect ratio (a.k.a. ratio of the dimple depth to dimple diameter), and the dimple arrangement on the processed surfaces [4]. In terms of texturing parameters and their influence on tribological properties, there is an agreement in the literature that an optimum aspect ratio can be found around $0.1[18,19,20]$ to about 0.18 [21] in a hydrodynamic lubrication regime. This ratio is also affected by the applied liquid lubricant. The viscosity of the lubricant and some of its other rheological properties determine the thickness of the lubricant fluid film [22]. There are publications finding the optimum at much smaller values around 0.01 , especially for very low viscosity mediums like water [23]. For much higher viscosity gear oils, the optimum dimple aspect ratio was reported to be around 1.0 [24].

For the tribological contact pairs of metals lubricated by oil, several studies under controlled laboratory conditions have been performed in order to analyze the effect of dimple area density on the friction coefficient. Several experimental researches show that the area density of dimples in the range of $5 \div 13 \%$ is preferable for friction reduction. Contact surface is reduced by the texture depressions to a sufficient extent in order to reduce the friction coefficient. The textured area density of above $20 \%$ usually causes increasing the friction coefficient and wear rate value $[22,25,26,27]$.

A third parameter that beckons investigation is how the individual depressions are arranged on the surface (depression orientation). Closely associated is the issue whether the texturing elements act alone or if they are affecting each other, working as a collective. The hypothesis exists that in case the dimples are not influencing each other, the friction force is expected to decrease linearly with increasing textured area [22, 28, 29]. Gachot et al. [30, 31] studied these influences for stainless steel surfaces which were treated by direct laser interference patterning. The authors concluded that the relative texture orientation has significant importance due to differences in contact area. But on the other hand, Saeidi [32] did not exhibit the significant effect of this parameter on the friction reduction.

Although various designs and optimisation of LST patterns have been investigated, the process design methods are still dominated by 'trial and error' approaches, and yet there are large variations in 'optimum' designs obtained by different research groups [33].

According to the review of current state of the art it was found that many experimental works deal with the optimizing of dimple-like depressions dimensions, in particular via a specific tribo-test in order to achieve the minimal friction coefficient and wear rate. However, there is a limited effort to the study the influence of such modified surfaces in real manufacturing processes, for instance in bulk material forming process, where the interaction between the forming tool and formed component is the most critical and important part of the process. Since the finished component can be considered as the result of this interaction. The influence of bulk compression process using the textured platens on the contact friction coefficient value on the forming tool formed component interface is primary studied in this article. The component surface roughness parameters and strain hardening are also experimentally analysed in order to gain a more complex and deeper view into the issue of laser-beam textured tools in a specific forming process.

\section{EXPERIMENTAL SETUP}

The morphological texturing of forming tool surfaces has a high potential to reduce friction and tool wear and also has impact on the surface layers properties (such as a micro-hardness or surface roughness) of formed material [24, 34, 35]. In order to understand the effect of different types of tool surface textures on the tribological 
conditions at the interface tool - formed material and on the integrity of formed part surface layers, the series of experimental investigations has been carried out. The main objective of this research article is to define the influence of the forming tools (planar platens in the gradual compression process of the test samples, as known as a Ringtest) on the chosen characteristics of the formed components. Contact pair in Ring-test consists of a pair of compression platens (upper-active and lower-static one) and the test sample, which is axially compressed among them. Frontal areas of each compression platen were covered by a texture with defined shape and dimensions by the laser surface texturing technology. 12 pairs of compression platens were used in the experiment; their frontal areas were modified by regularly arranged micro-depressions with a defined shape as follows:

1. Dimple - like depression: diameter of $100 \mu \mathrm{m}$, depth of about $20 \mu \mathrm{m}$.

2. Ellipsoid: length of $300 \mu \mathrm{m}$, width of $100 \mu \mathrm{m}$, depth of about $20 \mu \mathrm{m}$.

3. Circular groove: outer diameter of $240 \mu \mathrm{m}$, inner diameter of $140 \mu \mathrm{m}$, depth of about $20 \mu \mathrm{m}$.

4. "S" groove: the dimensions of this depression shape cannot be described in detail way, since this feature is a part of patent application process.
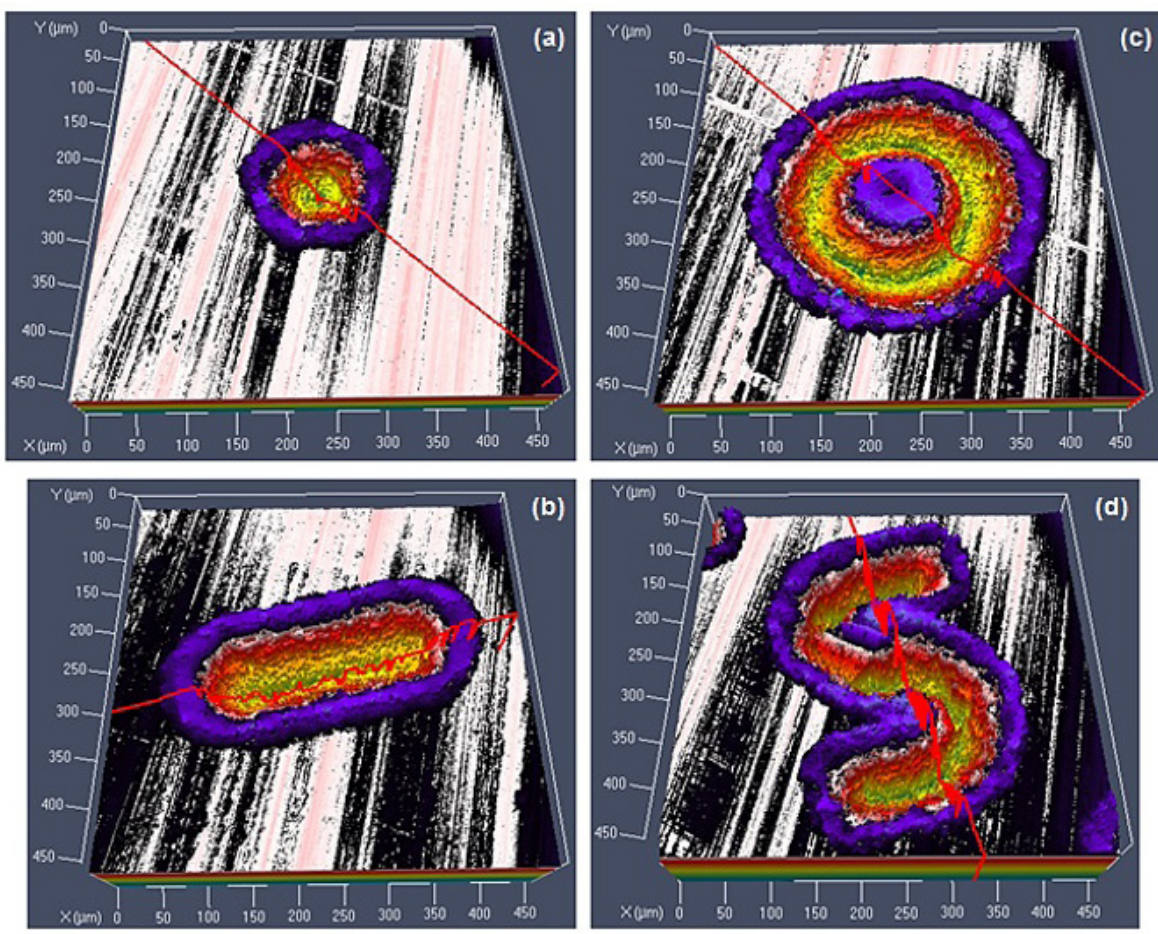

Fig. 1. 3D shapes of studied surface texture depressions: (a) dimple-like, (b) ellipsoid, (c) circular groove and (d) "S" groove
The first studied parameter of surface textures is the depression shape. The shapes of studied micro-dimples are depicted in Figure 1. Another studied parameter is the depressions arrangement, on the planar surface of the compression platens, relative to the material flow during the deformation process. The individual arrangements are depicted in Table 1 (enlargement of 50x) and can be described as follows:

1. Radial: the depressions are located on concentric circles; diameter of the circles increases gradually by a defined value, and with each subsequent circle the number of depressions located on that circle also increases.

2. Tetragonal: the depressions are located in the centre of the square sides with a defined side length.

3. Hexagonal: the depressions are located at the vertices of a regular hexagon with a defined side length; one depression is located at the centre of this formation.

4. The dimensions of the individual depression and their individual distance in the arrangement were calculated according to the surface texture density. This value is constant for each texture in this experimental research and is equal to $6 \%$, since the lower values are recommended for reduction of friction coefficient $[17,25,26]$. 
Table 1. Studied parameters of applied surface textures (depression shapes vs. arrangements)

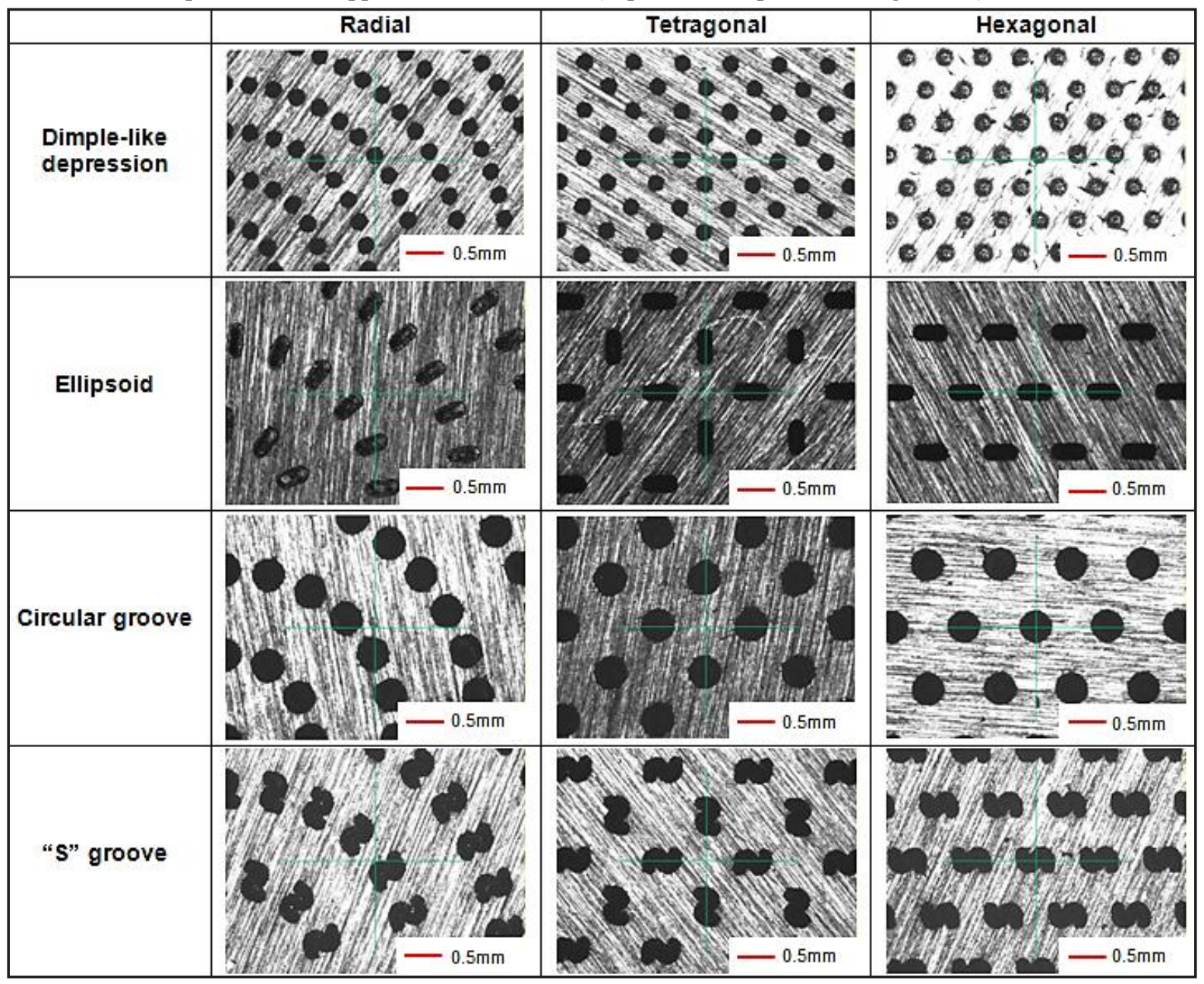

To manufacture the surface textures on the planar surfaces of compression platens a 5 -axis high precision laser micro-machining centre LaserTEC 80 Shape was used. This machine is equipped with a pulsed (pulse duration of $120 \mathrm{~ns}$ ) fibre ytterbium-based laser with a wavelength of $1064 \mathrm{~nm}$. The following constant laser beam parameters were used for the production of surface textures: output power of $16.40 \mathrm{~W}$, beam scanning speed of $1300 \mathrm{~mm} \cdot \mathrm{s}^{-1}$ and pulse repetition rate of $75 \mathrm{kHz}$. These parameters were optimized in order to achieve a depth of cut of $1 \mu \mathrm{m}$ per a layer.

A morphological analysis of chosen depression shape of each studied surface texture was performed in order to determine and verify the real shape and dimensions of depressions produced by laser beam micromachining. For this purpose, a laser confocal microscope Zeiss LSM 700 (resolution of $10 \mathrm{~nm}$ ) was used. Figure 1 shows the real shape and dimensions of studied depressions. It can be concluded, that all studied depressions fulfil the shape and the dimensional requirements, since the real dimensional variations can be negligible.

It can also be seen that around the edge of each studied depression a rim of solidified material was originated. This rim is a characteristic feature of the depressions manufactured by pulsed laser beam in a material ablation process $[36,37]$. This feature can have the negative effect in the friction-reducing applications. However, its effect can be minimalized by optimizing the laser beam parameters with a subsequent polishing of textured surfaces.

Compression platens were produced of $90 \mathrm{MnCrV} 8$ tool steel according to EN ISO 4957 standard, since this type of steel material is widely applied in production of tools for blank and bulk metal forming operations. Tab. 2 specifies the chemical composition of used tool steel; it is a low carbon steel suitable for construction and welding purposes.

Compression platens were produced by a turning technology, while the next operation was 
a quenching of the tools in the oil medium and their tempering to get the desired hardness of $60 \pm 1$ HRC. Subsequently, the tools planar areas were grinded to obtain a surface roughness $(\mathrm{Ra})$ of $0.8 \mu \mathrm{m}$; then were textured by laser beam.

It was demonstrated by the experimental research [3] that these solidified rims around the depressions edges have a negative effect on the tribological behaviour of contacting surfaces. Therefore it was necessary to remove these rims from all textured surfaces. So all the compression platens were polished with the polycrystalline diamond suspension (grain size of $1 \mu \mathrm{m}$, polishing time of $180 \mathrm{~s}$ ) using a Buehler AutoMet 300 polishing machine. The platens were subsequently cleaned in an ultrasonic bath which consists of an acetone medium heated up to $40{ }^{\circ} \mathrm{C}$ in order to all polishing suspension or steel debris were removed from the depressions (bath time of $120 \mathrm{~s}$ ).

A ring compression test in a lubrication-free regime (dry contact) was performed in order to determine the friction coefficient of the contact pairs $[17,38]$. During this test, a ring-shaped test sample, which is produced of S235JRG1 steel according to EN 10027-1 standard, is axially compressed among the pair of compression platens. This experimental testing was carried out using a universal testing machine Tinius Olsen 300ST, which is designed for tension, compression, flexure and shear strength testing of materials and assemblies. Chosen steels represent and simulate the standard materials of forming tool and the formed material which come into contact in most blank metal forming operations as well as bulk metal forming operations.

This Ring-test method is characteristic by the constant friction coefficient value at the whole tool - sample surface; what is more, the deformation of the test sample is homogeneous. During the compression of the test sample by the compression platens, the hole diameter can be lessened, remain without a change in diameter or can be even enlarged (according to the value of the friction coefficient). In this experimental research, the D:d:h ratio (ratio of the outer sample diameter $\mathrm{D}$ to the hole diameter $\mathrm{d}$ to the sample height $\mathrm{h}$ ) is equal to $6: 3: 2$. That means, that the dimensions of test samples are $12 \mathrm{~mm}: 6 \mathrm{~mm}: 4 \mathrm{~mm}$ according to this ratio. Planar frontal surfaces of test samples were non-textured; what is more, these surfaces were grinded to obtain a required surface roughness $(\mathrm{Ra})$ of $0.4 \mu \mathrm{m}$. It is recommended to preserve approximately an equal compression of test sample $\Delta \mathrm{h}$ during the test; while the constant value of $0.3 \mathrm{~mm}$ was selected. Compression of each test sample was performed four times. Figure 2 depicts a pair of textured compression platens together with the non-deformed (left) and deformed (right) test samples.

The friction coefficient values can be simply obtained for each sample compression, based on the relationship between the derived values of the inside diameter change and the percent axial reduction of the cylinder $\Delta \mathrm{h}$, which were depicted for the first time as an empirical system of calibration curves by Male and Cockcroft for a range of friction coefficient of 0.055 to 0.57 and the deformation up to 60 percent [39]. Coefficient of friction evaluation was performed at the room temperature of $22{ }^{\circ} \mathrm{C}$. Both, non-textured and textured compression platens were tested and studied in these conditions for comparison. Three test samples were gradually compressed in each combination of surface texture shape and arrangement, subsequently the average value of friction coefficient was calculated for each studied input parameters.

The experimental research was also focused on the analysis of the surface layers integrity of test samples material formed during the ring compression test, including surface roughness (Ra and Rz according to STN EN ISO 4287 standard) and sub-surface micro hardness (HV0.05); since during the compression test the analysed test piece surface layers integrity are heavily affected by the given surface texture of the compression platens. The relief of the surface texture is copied to the surface of the test sample and so the micropeaks on the test piece surface are subsequently generated. Fig. 3 depicts the difference between the surface conditions of the non-deformed and the deformed test piece. It can be clearly seen that the surface of the deformed test piece is covered by the micro-peaks, which were generated by the

Table 2. Chemical composition of applied low carbon and tool steels (in wt \%)

\begin{tabular}{|c|c|c|c|c|c|c|c|c|c|}
\hline & $\mathrm{C}$ & $\mathrm{Mn}$ & $\mathrm{P}$ & $\mathrm{S}$ & $\mathrm{Si}$ & $\mathrm{Cr}$ & $\mathrm{N}$ & $\mathrm{V}$ & $\mathrm{Mo}$ \\
\hline 90MnCrV8 & 0.91 & 1.98 & 0.03 & 0.03 & 0.17 & 0.37 & - & 0.13 & - \\
\hline S235JRG1 & 0.17 & - & 0.045 & 0.045 & - & - & 0.007 & - & - \\
\hline
\end{tabular}




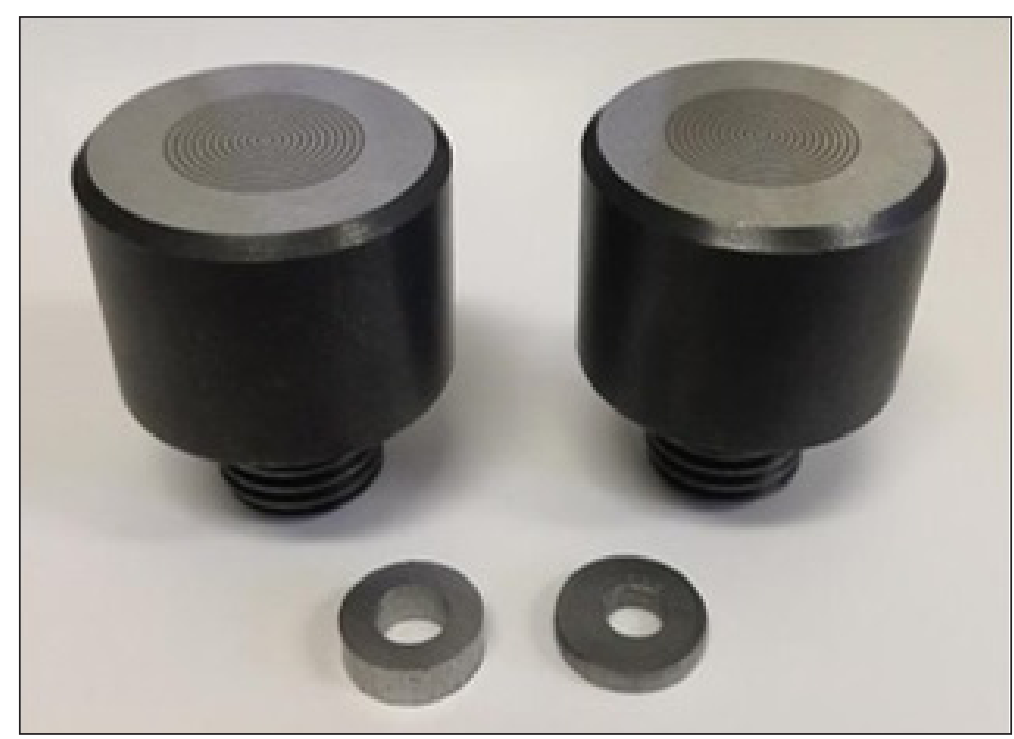

Fig. 2 A pair of textured compression platens with the non-deformed (left) and deformed (right) test piece

micro-forming process during the compression. In this case, surface micro-peaks are generated according to the "S" groove depressions, which are hexagonally arranged.

Surface roughness measurement (a maximum height of the scale limited surface Rz and an arithmetical mean height of the scale limited surface $\mathrm{Ra}$ ) was carried out using a Zeiss Surfcom 5000 measuring system. The measuring principle is depicted in Figure 3. The tactile device path is located across the macimum number of the micro-peaks through its middle, while the chosen evaluated length is $4 \mathrm{~mm}$ and the tactile device movement speed is $0.15 \mathrm{~mm} \cdot \mathrm{s}^{-1}$.
Micro-hardness measurement was carried out in order to determine the influence of surface textures (various depression shapes and the arrangements) on the strain rate of the test samples after the compression process, using a BUEHLER Indentamet 1105 device with SW Omnimet MHT. Test samples were vertically sawn up through the midpoints and prepared for the sub-surface micro-hardness measurement by the specific set of procedures (compression mounting, grinding and polishing of the samples). The individual measuring points are depicted in Figure 4; the distance between the measuring points is equal to $0.5 \mathrm{~mm}$ from the top surface. The measured points are

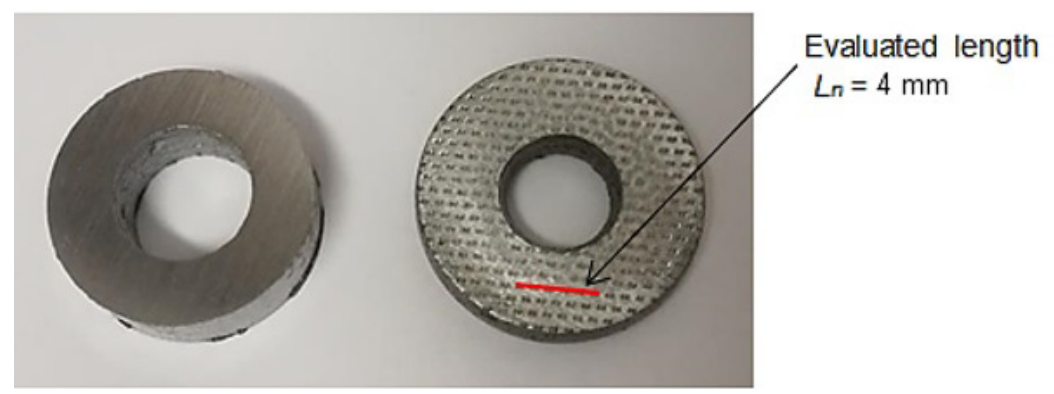

Fig. 3. Surface conditions between the non-deformed (left) and deformed (right) test piece

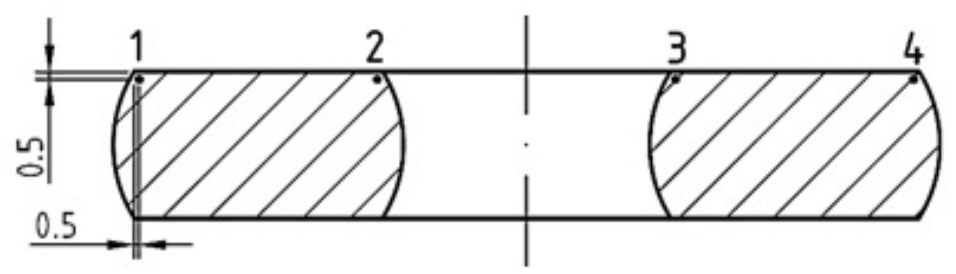

Fig. 4. Micro-hardness measuring points 
placed to the zone of increased plastic deformation; therefore, there are maximum strains in this zone. The points are located to the outer and inner edge of the test sample with the distance of 0.5 $\mathrm{mm}$ from these edges.

In order to quantify the effects of the studied factors and interactive influences among them on the friction coefficient values, the analysis of variance (ANOVA) using Minitab v.17 software was carried out. The number of 2 replicates was chosen for each base run, which means the total number of runs is 24 in this analysis. The Fisher's ratio (F-ratio), which is the ratio between the variance due to the effect of a factor and the variance due to an error term, was used to measure the significance of the factor at the desired significance level. If the F-value is greater than the tabulated $F_{\text {crit }}$ value, the process parameter is considered as significant.

\section{RESULTS AND DISCUSSION}

Friction coefficient values along with its standard deviations for a different combination of studied input factors (depression shape and the depression arrangement) obtained via a Ringcompression test are summarized in Table 3. Ring-compression test for non-textured compression platens was carried out too, this compression conditions are labelled as a Reference value, what corresponds to the friction pair consisting of two only grinded steel surfaces. The friction coefficient value for this reference sample is equal to $0.256 \pm 0.013$. It is important to mention that all studied surface textures, more or less contributed to the friction coefficient value reduction compared to the reference value in lubrication-free regime. Table 3 also presents the maximum friction coefficient reduction which was recorded for a specific surface texture with the lowest friction coefficient (bolded value) in comparison to the reference value.
Figure 5 shows the friction coefficient evaluation for individual depression shape depending on the depression arrangement. The lowest friction coefficient value was reached for the dimplelike depression which is radially arranged on the planar surface of the compression platen. In this case, the friction coefficient reaches the value of 0.156 , which means that the maximum reduction in friction coefficient is $39.1 \%$. Similar results were obtained for dimple-like depressions arranged to tetragon and hexagon, where the friction coefficient reduction was observed of $30.5 \%$ and $33.6 \%$ respectively.

In the case of "S" groove depression shape it can be concluded that the influence of the depression arrangement as the input factor on the friction coefficient value can be statistically negligible, since the friction coefficient values vary in the very narrow interval from 0.167 (hexagonal arrangement, friction reduction of $34.8 \%$ ) to 0.177 (tetragonal arrangement, friction reduction of $30.9 \%$ ). The results for this type of depression shape are very similar to the dimple-like depression ones.

A similarity of studied results was observed for ellipsoid and circular groove depression shape. Friction coefficient values in these cases vary in a similar range, as can be seen in Figure 5. Almost equal values of friction coefficients are obtained in the case of ellipsoid depression shape arranged to tetragon (friction coefficient of 0.203) and then arranged to hexagon (friction coefficient of 0.205 ) and for circular groove depression shape arranged to radial layout (friction coefficient of 0.199 ) and then to tetragon (friction coefficient of 0.20 ). The average friction coefficient reduction is about $21 \%$.

For the future experimental researches, it is recommended to verify these results by application of another type of tribo-test, for instance Pin-on-Disc configuration, in order to quantify the reliability and the accuracy of Ring-compression test and to compare the results of the friction

Table 3. Friction coefficient values for different depressions shapes and arrangements

\begin{tabular}{|l|c|c|c|c|}
\hline & Radial & Tetragonal & Hexagonal & $\begin{array}{c}\text { Maximum friction } \\
\text { reduction }\end{array}$ \\
\hline Dimple-like & $0.156 \pm 0.063$ & $0.178 \pm 0.058$ & $0.170 \pm 0.022$ & $39.1 \%$ \\
\hline Ellipsoid & $0.168 \pm 0.059$ & $0.203 \pm 0.048$ & $0.205 \pm 0.044$ & $34.4 \%$ \\
\hline Circular Groove & $0.199 \pm 0.048$ & $0.200 \pm 0.031$ & $0.188 \pm 0.050$ & $26.6 \%$ \\
\hline "S" groove & $0.169 \pm 0.042$ & $0.177 \pm 0.026$ & $0.167 \pm 0.033$ & $34.8 \%$ \\
\hline Reference value & \multicolumn{3}{|c|}{$0.256 \pm 0.013$} \\
\hline
\end{tabular}



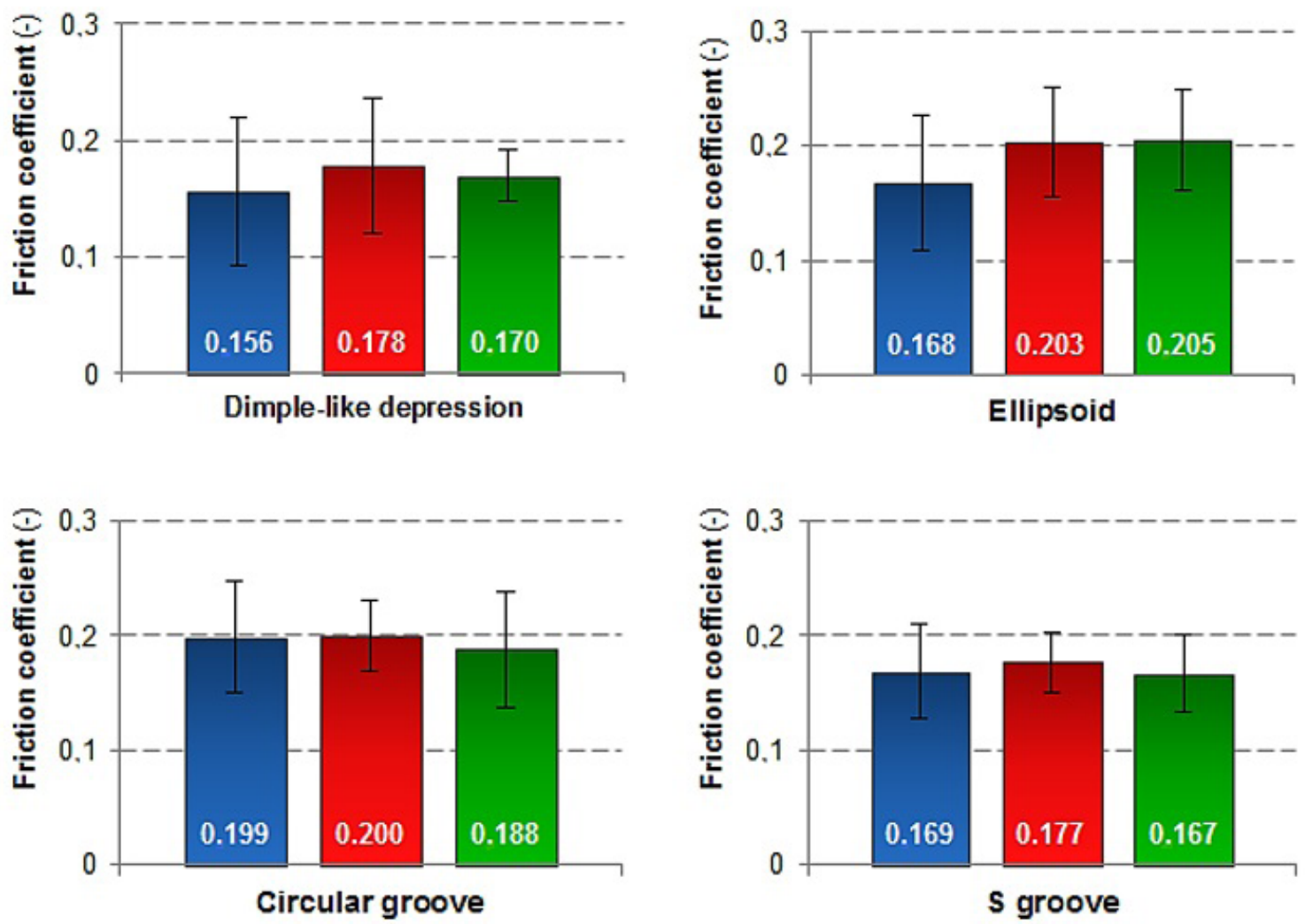

Fig. 5. Friction coefficient values depending on the depression shape vs. depression arrangement - radial, - tetragonal, - hexagonal

coefficient values with the experimental results achieved worldwide.

The results of the ANOVA analysis and Fvalue for friction coefficient as studied response are shown in Table 4 . The results revealed that both of the input studied parameters (depression shape and the depression arrangement) can be considered as significant. The influence of these parameters on the studied response is statistically important, which is also confirmed by the calculated $p$-value in Table 4. If the calculated p-value is lower than the confidence level $(\alpha=0.05)$, than the factor can be considered as statistically significant, while the shape input parameter shows a higher degree of significance than the arrangement parameter.

Another studied response was the test pieces surface roughness measured on both planar frontal areas after its plastic deformation by the compression platens, while one test piece was measured for one combination of surface texture parameters. Surface profile parameters $\mathrm{Ra}$ and $\mathrm{Rz}$ were chosen as the studied responses, the results for each specific combination of input parameters are summarised in Table 5. These values are subsequently compared to the reference value (RV, Ra of 0.41 $\mu \mathrm{m}$ and $\mathrm{Rz}$ of $0.99 \mu \mathrm{m})$, which corresponds to the non-textured pair of compression platens.

Table 4. Analysis of Variance - Coefficient of friction

\begin{tabular}{|l|c|c|c|c|c|}
\hline \multicolumn{1}{|c|}{ Source } & DF & $\begin{array}{c}\text { Sum of } \\
\text { Squares }\end{array}$ & Mean Square & F-Value & $p$-Value \\
\hline Model & 11 & 0.00611 & 0.00056 & 6.16 & 0.002 \\
\hline Shape & 3 & 0.00377 & 0.00126 & 13.95 & ${ }^{*} 0.001$ \\
\hline Arrangement & 2 & 0.00094 & 0.00047 & 5.20 & ${ }^{*} 0.024$ \\
\hline Shape*Arrangement & 6 & 0.00140 & 0.00023 & 2.58 & 0.076 \\
\hline Error & 12 & 0.00108 & 0.00009 & & \\
\hline Total & 23 & 0.00719 & & & \\
\hline
\end{tabular}

Tabulated Fcrit at $95 \%$ confidence level: Fcrit $(0.05 ; 3 ; 12)=3.49 ;$ Fcrit $(0.05 ; 2 ; 12)=3.88$;

Fcrit $(0.05 ; 6 ; 12)=2.98 ; \mathrm{R}-\mathrm{sq}=85.1 \%, \mathrm{R}-\mathrm{sq}(\operatorname{adj})=71.5 \%$, base runs: 12 ; replicates: 2 ; total runs: 24 
Table 5. Surface roughness values for different depressions shapes vs. arrangements

\begin{tabular}{|c|c|c|c|}
\hline Depression shape & Arrangement & Ra $(\mu \mathrm{m})$ & $\mathrm{Rz}(\mu \mathrm{m})$ \\
\hline \multirow{3}{*}{ Ellipsoid } & Radial & 2.20 & 18.63 \\
\cline { 2 - 4 } & Hexagonal & 1.83 & 12.55 \\
\cline { 2 - 4 } & Tetragonal & 1.97 & 16.31 \\
\hline \multirow{3}{*}{ Dimple-like } & Radial & 2.19 & 16.79 \\
\cline { 2 - 4 } & Hexagonal & 1.26 & 15.33 \\
\cline { 2 - 4 } & Tetragonal & 2.02 & 16.95 \\
\hline \multirow{3}{*}{ Circular groove } & Radial & 2.25 & 16.76 \\
\cline { 2 - 4 } & Hexagonal & 2.01 & 22.25 \\
\cline { 2 - 4 } & Tetragonal & 2.52 & 14.61 \\
\hline \multirow{2}{*}{ "S" groove } & Radial & 3.11 & 17.45 \\
\cline { 2 - 4 } & Hexagonal & 2.29 & 0.99 \\
\hline
\end{tabular}

Maximum and minimum values of $\mathrm{Ra}$ and $\mathrm{Rz}$ for a specific combination of input parameters are also marked, as bolded in Table 5. As it can be seen, the maximum values were obtained for surface texture consisting of "S" grooves arranged radially ( $\mathrm{Ra}$ of $3.11 \mu \mathrm{m}$ and $\mathrm{Rz}$ of 22.07 $\mu \mathrm{m})$. Surface roughness profile for these conditions is depicted in Figure 6a. On the other hand, the minimum values for $\mathrm{Ra}$ and $\mathrm{Rz}$ were obtained using surface texture parameters: dimple-like depressions arranged in hexagonal layout ( $\mathrm{Ra}$ of 1.26 and $\mathrm{Rz}$ of 12.53). Roughness profile for this surface is presented in Figure 6b.

It can be concluded that the process of plastic deformation by application of textured compression platens contributes to the considerable (mul- tiple) increase of the studied surface roughness parameters compared to the reference sample, while no matter the depression shape or its arrangement. The reason of this fact is that during the compression test the surface texture depressions of the platens are filled up by the test sample material. The micro-peaks, with the identical dimensions and arrangement as the applied surface texture, are formed on the planar surfaces of the test piece, as it can be seen in Figure 3.

The last objective was to define the effect of the compression platens surface texture on the strain hardening of the test sample material via the measuring of the sub-surface micro-hardness in the individual points according to the above defined procedure.

a)

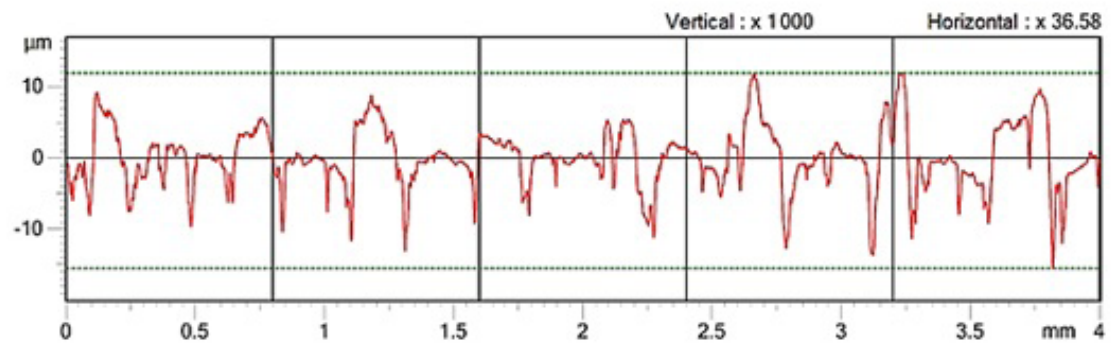

b)

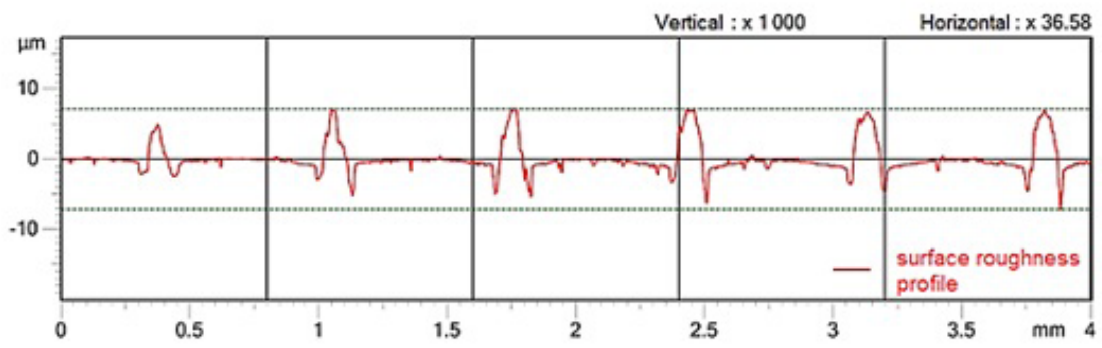

Fig. 6. Surface roughness profile for "S" grooves/radial (a) and surface roughness profile for dimple-like depressions/hexagonal (b) 
The obtained micro-hardness values for the individual measuring points are summarized in Table 6 . These values are subsequently compared to the Reference values which were obtained by application of the non-textured pair of compression platens. A graphical representation of the micro-hardness evaluation for each analysed parameter is shown in Figure 7.

As it can be seen in Tab. 6, the compression process caused unequal strains in the bulk mate- rial of the test samples, which resulting from the size of external contact friction in particular. Friction on the contact surfaces also causes the uneven distribution of the forming pressure, which results in formation of the barrelled shape of the test samples. It is apparent from Figure 7 that the strain hardening value of the test samples material gradually increases from the outer edge of the sample to its inner edge. This is true in all studied combination of the parameters.

Table 6. Sub-surface micro-hardness values for different depressions shapes vs. arrangements

\begin{tabular}{|c|c|c|c|c|c|}
\hline Depression shape & Arrangement & $\begin{array}{c}1 \\
(\mathrm{HV} 0.05)\end{array}$ & $\begin{array}{c}2 \\
(\mathrm{HV0.05})\end{array}$ & $\begin{array}{c}3 \\
(\mathrm{HV} 0.05)\end{array}$ & $\begin{array}{c}4 \\
(\mathrm{HV0}) .05)\end{array}$ \\
\hline \multirow{3}{*}{ Ellipsoid } & Radial & 262.3 & 301.0 & 289.9 & 259.2 \\
\cline { 2 - 6 } & Hexagonal & 286.2 & 319.8 & 292.6 & 276.6 \\
\cline { 2 - 6 } & Tetragonal & 275.4 & 299.4 & 331.4 & 276.9 \\
\hline \multirow{3}{*}{ Dimple-like } & Radial & 244.6 & 294.6 & 322.7 & 250.2 \\
\cline { 2 - 6 } & Hexagonal & 220.6 & 281.5 & 292.6 & 237.6 \\
\cline { 2 - 6 } & Tetragonal & 256.8 & 320.8 & 302.8 & 248.9 \\
\hline \multirow{3}{*}{ Circular groove } & Radial & 282.6 & 371.4 & 382.7 & 286.2 \\
\cline { 2 - 6 } & Hexagonal & 271.0 & 307.6 & 304.2 & 268.4 \\
\cline { 2 - 6 } & Tetragonal & 266.6 & 302.8 & 304.5 & 270.9 \\
\hline \multirow{3}{*}{ "S" groove } & Radial & 259.6 & 311.6 & 309.8 & 265.1 \\
\cline { 2 - 6 } & Hexagonal & 278.4 & 306.2 & 296.0 & 273.9 \\
\cline { 2 - 6 } & Tetragonal & 256.8 & 299.4 & 307.6 & 284.6 \\
\hline Reference values & - & 276.9 & 313.4 & 299.3 & 283.0 \\
\hline
\end{tabular}
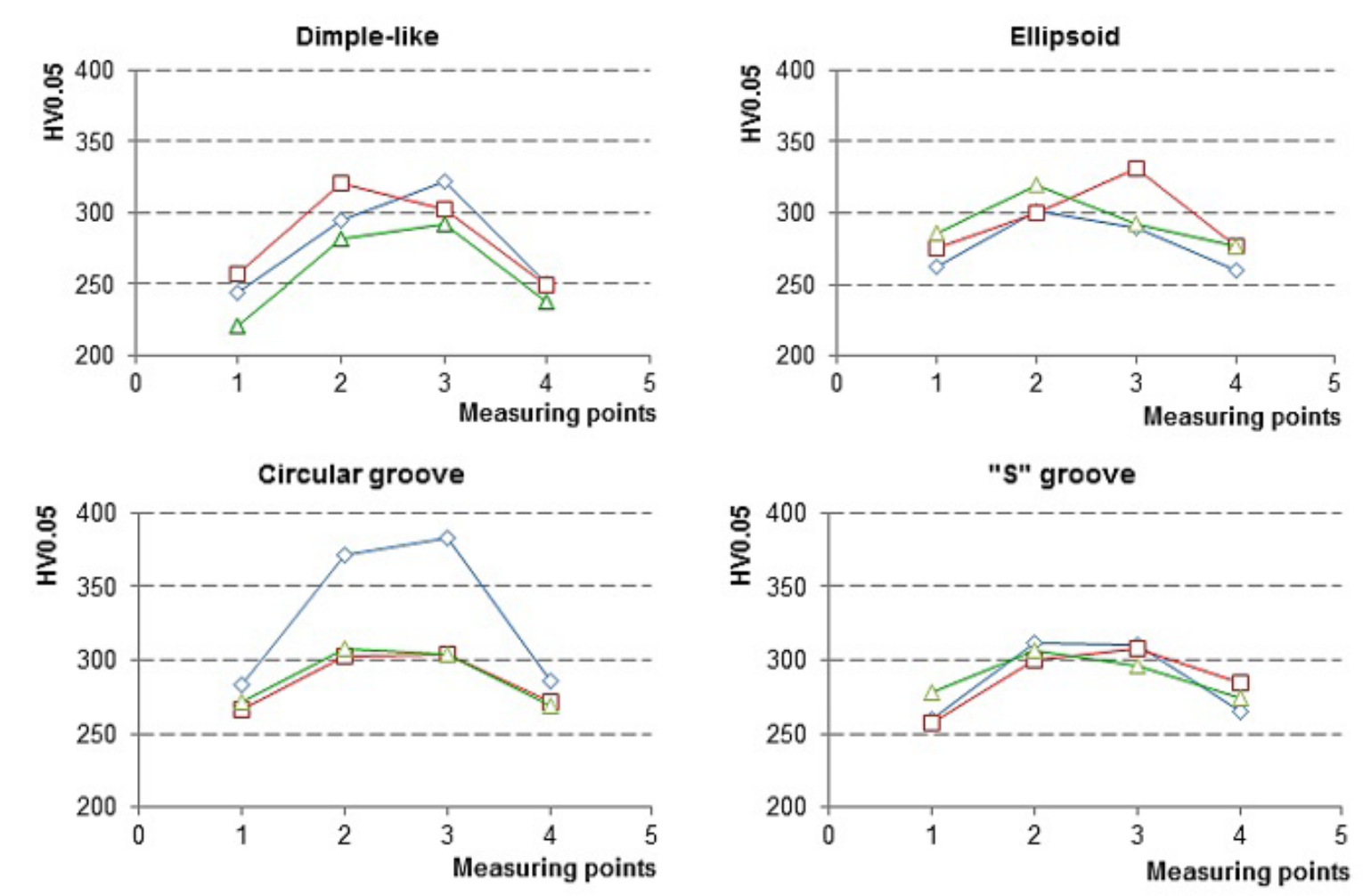

Fig. 7. Micro-hardness evaluation based on different surface texture parameters

- radial, $\square$ - tetragonal, $\mathbf{0}$ - hexagonal 
In this case, it is not possible to make a clear conclusion about the influence of the surface texture on the size of the strain hardening of the analysed test samples. As the experiment shows, the values of the material strain hardening for the applied surface textures vary around the reference values. The biggest increase in the studied response was observed for the circular groove depressions which are radially arranged; the values of strain hardening increased by $13 \%$ on average. Additionally, the biggest decrease of the studied response was observed for the dimple-like depressions arranged hexagonally, the values of strain hardening decreased by $11.6 \%$ on average.

It can be assumed in general that the surface textures which contribute to a more significant reduction of friction coefficient (is valid for dimple-like and "S“ groove depressions, no matter the depression arrangement) also exhibit the lower values of strain hardening of the test sample material compared to the reference value. On the other hand, surface textures consisting of the ellipsoid or the circular groove depressions show the increasing of the strain hardening values compared to the reference values.

\section{CONCLUSION}

The presented experimental research was focused on the influence analysis of the tool surface texture parameters (depression shapes and their arrangement) on the friction coefficient value primary and on the component surface layers properties secondary. Various types of surface textures were prepared on the planar surfaces of the compression platens by application of laser micro-machining technology. The studied responses were primary the tribological behaviour (size of the friction coefficient) of the contact pair consisting of the textured forming tool and the formed test sample and also the integrity of formed sample surface layers (surface roughness parameters Ra, $\mathrm{Rz}$ and sub-surface micro-hardness) secondary. The following conclusions can be drawn based on the experimental results:

- tool surface texture contributes to the significant reduction of the contact friction coefficient measured on the tool-formed material interface in a lubrication-free regime. From the maximum reduction of friction point of view, the ideal tool surface texture is constituted by dimple-like depressions arranged in radial lay- out. Maximum friction coefficient reduction was observed of about $40 \%$ in this case.

- Minimal friction coefficient reduction of around $20 \%$ was observed using the textured compression platens.

- ANOVA results shown that both of the studied texture parameters (the depressions shape and their arrangement on the planar surface of the compression platens) have a significant effect on the size of the friction coefficient, these parameters are statistically significant.

- However, the tool surface texture influences the surface roughness parameters $\mathrm{Ra}$ and $\mathrm{Rz}$ of the test sample material during the compression process, and in particular, the Rz parameter is significantly affected. Test sample material fills up volume of the surface texture depressions and therefore, a surface texture with a negative shape in the form of protrusions is formed on the test sample surface.

- With the reduction of friction coefficient, a decrease in the size of the test sample material strain hardening is also observed in certain and specific cases. However, this phenomenon cannot be clearly confirmed, since on the other hand, specific combinations of surface texture parameters lead to increasing of the strain hardening compared to the reference value.

\section{Acknowledgement}

This research was supported by an international research project under the MANUNET 2014 call, entitled: Innovative methods of sheet metal forming tools surfaces improvement $-R \& D$ (2014/11283); and VEGA project: Laser surface texturing technology research for an optimizing of tribology conditions in the sheet metal forming processes (1/0669/15) and the authors would also like to thank for financial contribution from the STU Grand Scheme for Support of Young Researchers (SURFTOOL 1386 project).

\section{REFERENCES}

1. Jones K. and Schmid S.R. Experimental Investigation of Laser Texturing and Its Effect on Friction and Lubrication. Procedia Manufacturing, 5(2016), 568-577.

2. Meng F., Zhou R., Davis T. et al. Study on effect of dimples on friction of parallel surfaces under different sliding conditions. Applied Surface Science, 256(2010), 2863-2875. 
3. Kovalchenko A., Ajayi O., Erdemir A. et al. The effect of laser surface texturing on transitions in lubrication regimes during unidirectional sliding contact. Tribology International, 38(2005), 219 - 225.

4. Greiner Ch., Merz T., Braun D. et al. Optimum dimple diameter for friction reduction with laser surface texturing: the effect of velocity gradient. Surface Topography: Metrology and Properties, 3(2015), 044001.

5. Etsion I. State of the art in laser surface texturing. Journal of Tribology, 127(2005), 248 - 253.

6. Borghi A., Gualtieri E., Marchetto D. et al. Tribological effects of surface texturing on nitriding steel for high-performance engine applications. Wear, 265(2008), 1046 - 1051.

7. Kummel J., Braun D., Gibmeier J. et al. Study on micro texturing of uncoated cemented carbide cutting tools for wear improvement and built-up edge stabilisation. Journal of Materials Processing Technology, 215(2015), $62-70$.

8. 8ZumGahr K.H., Wahl R. and Wauthier K. Experimental study of the effect of microtexturing on oil lubricated ceramic/ steel friction pairs. Wear, 267(2009), $1241-1251$.

9. Kawasegi N., Sugimori H., Morimoto H. et al. Development of cutting tools with microscale and nanoscale textures to improve frictional behaviour. Precision Engineering, 33(2009), 248 - 254.

10. Geiger M., Roth S. and Becker W. Influence of laser-produced microstructures on the tribological behavior of ceramics. Surface and Coatings Technology, 100-101(1998), $17-22$.

11. Kim D.E., Cha K.H., Sung I.H. et al. Design of surface micro-structures for friction control in microsystems applications. CIRP Annals - Manufacturing Technology, 51(2002), 495 - 498.

12. Costa H.L. and Hutchings I.M. Hydrodynamic lubrication of textured steel surfaces under reciprocating sliding conditions. Tribology International, 40(2007), $1227-1238$.

13. Suh M.-S., Chae Y.-H., Kim S.-S. et al. Effect of geometrical parameters in micro-grooved crosshatch pattern under lubricated sliding friction. Tribology International, 43(2010), 1508 - 1517.

14. Wang L. Use of structured surfaces for friction and wear control on bearing surfaces. Surface Topography: Metrology and Properties, 2(2014), 043001.

15. Rapoport L., Moshkovich A., Perfilyev V. et al. Friction and wear of MoS2 films on laser textured steel surfaces. Surface and Coatings Technology, 202(2008), $3332-3340$.

16. Gachot C., Rosenkranz A., Hsu S.M. et al. A critical assessment of surface texturing for friction and wear improvement. Wear, 372-373(2017), 21 - 41.

17. Šugárová J., Frnčík M., Necpal M. et al. Evaluation of tribological properties of laser textured hardened tool steels. Zeszyty naukowe Politechniki Rzeszowskiej: Mechanika, 88(2016), 233 - 245.

18. Kligerman Y., Etsion I. and Shinkarenko A. Improving tribological performance of piston rings by partial surface texturing. Journal of Tribology, 127(2005), $632-638$.

19. Yan D., Qu N., Li H. et al. Significance of dimple parameters on the friction of sliding surfaces investigated by orthogonal experiments. Tribology Transactions, 53(2010), $703-712$.

20. Shinkarenko A., Kligerman Y. and Etsion I. The validity of linear elasticity in analyzing surface texturing effect for elastohydrodynamic lubrication. Journal of Tribology, 131(2009), 021503.

21. Ronen A., Etsion I. and Kligerman Y. Frictionreducing surface-texturing in reciprocating automotive components. Tribology Transactions, 44(2001), $359-366$.

22. Schneider J., Braun D. and Greiner Ch. Laser Textured Surfaces for Mixed Lubrication: Influence of Aspect Ratio, Textured Area and Dimple Arrangement. Lubricants, 5(2017), 5030032.

23. Ripoll M.R., Simič R., Brenner J. et al. Friction and lifetime of laser surface-textured and MoS2coated Ti6Al4V under dry reciprocating sliding. Tribology Letters, 51(2013), $261-271$.

24. Lu X. and Khonsari M.M. An experimental investigation of dimple effect on the Stribeck curve of journal bearings. Tribology Letters, 27(2007), $169-176$

25. Tang W., Zhou Y., Zhu H. et al. The effect of surface texturing on reducing the friction and wear of steel under lubricated sliding contact. Applied surface science, 273(2013), 199 - 204.

26. Wang X., Wang J., Zhang B. et. al. 2015 Design principles for the area density of dimple patterns. Journal of Engineering Tribology, 229(2015), $538-546$.

27. Ibatan T., Uddin M.S. and Chowdhury M.A.K. Recent development on surface texturing in enhancing tribological performance of bearing sliders. Surface \& Coatings Technology, 272(2015), $102-120$.

28. Peng X.D., Sheng S.E., Li J.Y. et al. Effects of dimple geometric parameters on the performance of a laser-textured mechanical seal. Key Engineering Materials, 373-374(2008), 766 - 769.

29. Brizmer V., Kligerman Y. and Etsion I. A laser surface textured parallel thrust bearing. Tribology Transactions, 46(2003), 397 - 403.

30. Gachot C., Rosenkranz A., Reinert L. et al. Dry friction between laser-patterned surfaces: role of alignment, structural wavelength and surface chemistry. Tribology Letters, 49(2013), 193 - 202. 
31. Prodanov N., Gachot C., Rosenkranz A. et al. Contact mechanics of laser-textured surfaces. Tribology Letters, 50(2013), $41-48$.

32. Saeidi F., Meylan B., Hoffmann P. et al.: Effect of surface texturing on cast iron reciprocating against steel under starved lubrication conditions: A parametric study. Wear, 348-349(2016), 17 - 26.

33. Bhaduri D., Batal A., Dimov S.S. et al. On design and tribological behaviour of laser textured surfaces, Procedia CIRP, 60(2017), 20 - 25.

34. Gualtieri E., Borghi A., Calabri L. et al. Increasing nanohardness and reducing friction of nitride steel by laser surface texturing. Tribology International, 42(2009), 699 - 705.

35. Vilhena L.M., Sedlaček M., Podgornik B. et al.
Surface texturing by pulsed Nd:YAG laser. Tribology International, 42(2009), 1496 - 1504.

36. Šugár P., Šugárová J. and Frnčík M. Laser surface texturing of tool steel: textured surface quality evaluation. Open Engineering, 6(2016), 90 - 97.

37. Guo J., Li Y., Lu H. et al. An effective method of edge deburring for laser surface texturing of $\mathrm{Co}$ Cr-Mo alloy. The International Journal of Advanced Manufacturing Technology, 2017, In press.

38. Šugárová J., Šugár P. and Frnčík M. Friction evaluation of laser textured tool steel surfaces. Acta Mechanica et Automatica, 11(2017), 129 - 134.

39. Mielnik E. M. 1991. Metalworking science and engineering. Ney York: McGraw-Hill, 976 p. ISBN 0-07-041904-3. 